\title{
Perceived stress and well-being in UK and \\ Australian Dental Hygiene and Dental Therapy \\ Students
}

\section{Harris, ${ }^{* 1}$ J.C. Wilson, ${ }^{2}$ S. Hughes,${ }^{3}$ R.J.M. Knevel ${ }^{4}$ and D.R. Radford ${ }^{5}$}

${ }^{\star 1}$ PhD student; University of Portsmouth Dental Academy

${ }^{2}$ Reader in Applied Psychology; University of Portsmouth

${ }^{3}$ Associate Dean, Education and Student Affairs. Professor of Clinical and Restorative Dental Sciences; University of California, San Francisco

${ }^{4}$ Senior Lecturer, PhD student. Department of Dentistry and Oral Health; La Trobe Rural Health School

${ }^{5}$ Reader/Hon Consultant, Integrated Dental Education and Multi-Professional Care; King's College London Dental Institute and the University of Portsmouth Dental Academy

Correspondence to: Marina Harris*

University of Portsmouth, Faculty of Science, William Beatty Building, Hampshire Terrace, Portsmouth. PO1, 2QG.

marina.harris@myport.ac.uk

\section{ACKNOWLEDGEMENTS}

Funding for this study was from the University of Portsmouth, as part of the first author's PhD studentship. 


\section{Perceived stress and well-being in UK and Australian Dental Hygiene and Dental Therapy students}

\section{ABSTRACT}

Introduction: This study aimed to explore United Kingdom (UK) and Australian (Aus) Dental Hygiene and Dental Therapy Students' (DHDTS) perception of stress and wellbeing during their undergraduate education. Upon qualification, DHDTS in the UK register as Dental Therapists (DT), and in Australia they register as Oral Health Therapists (OHT).

Materials and methods: A questionnaire was distributed to Years 1, 2 and 3 DHDTS at the University of Portsmouth Dental Academy (UPDA) in the UK, and La Trobe Rural Health School in Australia. The questionnaire consisted of five well-used measurement instruments which included the: Dental Environment Stress questionnaire (DES); Depression Anxiety Stress Scales (DASS-21); Scales of Psychological Well-Being (SPWB); Valuing Questionnaire (VQ); and the Adult Hope Scale (AHS) to collect data on students' perception of levels of stress and well-being.

Results: A response rate of 58\% (UK) and 55\% (Australia) was achieved. Clinical factors and academic work were perceived as stressful for DHDTS in both the UK and Australia. The Australian DHDTS perceived stress in the educational environment was significantly higher $(p<0.002)$ than the UK DHDTS. The majority of respondents reported levels of depression, anxiety, and stress to be within the normal-to-moderate range. All students reported high levels of positive well-being, with no significant differences between the two groups.

Conclusions: DHDTS in the UK and Australia identified sources of stress within their undergraduate education, but also perceived themselves as positively-functioning individuals.

Key words: Australia, Dental Hygienist and Dental Therapist students, stress, United Kingdom, well-being. 


\section{INTRODUCTION}

Studies have shown that the dental school undergraduate environment is a highly demanding and stressful learning experience for a number of students, potentially leading to burnout and affecting academic performance ${ }^{1-6}$ Three recent studies which examined stress and well-being among dental hygiene and dental therapy students (DHDTS) in the United Kingdom (UK) and in South Africa (SA), ${ }^{7-9}$ showed that DHDTS perceived sources of stress within their undergraduate programme were comparable to reported findings amongst dental students. ${ }^{10,11}$ In the first of these studies, ${ }^{7}$ valid and reliable measures of well-being ${ }^{12-14}$ in conjunction with the widely-used Dental Environment Stress questionnaire (DES), ${ }^{15}$ were used to explore dimensions of well-being, as well as stress. The studies demonstrated that DHDTS reported similar sources of stress to that of dental students (e.g. examinations and grades, workload, and graduation requirements). However, the DHDTS, unlike the dental students, also reported high scores in psychological well-being dimensions, specifically in: goals, purpose in life, personal growth, and living a valued life..$^{7,8}$

In a second study, ${ }^{8}$ the same researchers used the baseline data on DHDTS stress and well-being, to formulate semi-structured interview questions to conduct a qualitative followon study. This study showed that the majority of participants derived a sense of fulfilment from aspects of their undergraduate programme that they perceived as stressful. Moreover, thematic analysis suggested that a strong sense of passion to become a clinician mitigated most, but not all, of the stressful experiences of the DHDTS undergraduate learning environment. For example, participants highlighted aspects of the learning environment that were difficult, negative, and disappointing (e.g. criticism of their clinical work). However, they utilised the feedback as an opportunity to learn and grow; even where there were instances of conflicting opinions from the clinical teaching staff. ${ }^{8}$

Whilst these three studies have contributed to the gap in knowledge and offered insight into stress and well-being amongst DHDTS in two institutions, there needs to be a clearer understanding of perceived stress and well-being among DHDTS in other institutions, and in other countries. For example, what role the institutional environment and curriculum has on students' perceptions. ${ }^{16}$ The aim of this study therefore was to compare the perceived sources of stress and well-being in DHDTS studying in a dental school in the UK and in Australia, so that we can understand if both groups of students experience similar or different levels of stress and well-being throughout their training to become qualified 
clinicians within their scope of practice. Moreover, considering that the role of the dental undergraduate provider is to equip DHDTS with the appropriate skills to join their profession, it is vital that (as with dental students) their stress and well-being is explored. Indeed, in the very few studies which have explored stress and wellbeing among qualified dental hygienists, the researchers identified lack of stress-resilience education within the undergraduate curriculum as a precursor to stress and burnout in the dental hygiene profession. ${ }^{17,18}$

To contextualise the study, Table 1 presents the DHDTS curriculum for the UK and La Trobe Rural Health School, which is currently one of only a few accredited programmes in Australia that prepares graduates to restore teeth in adults of all ages. The educational approach for both the study samples were similar with respect to the academic requirements to enrol on the course, as well as a similar course content with a few variations in when it is delivered. Both universities make use of digital portfolios to track students' progress throughout the course, with pre-clinical and clinical hurdles to guarantee patient safety. However, unlike the UK DHDTS, where the practical elements of the course are all tutor-lead, the majority of the pre-clinical sessions for the Australian DHDTS use a 'flipped classroom' concept, where students prepare before attending the session by engaging in prereading and watching instructional videos. In the pre-clinical session itself, the Australian DHDTS are expected to try and start the procedure without additional tutor demonstrations, with supervision and personal feedback provided. Upon qualification, DHDTS in the UK register as Dental Therapists, and in Australia they register as Oral Health Therapists.

\section{MATERIALS AND METHODS}

Ethical approval was gained from the University of Portsmouth Research Ethics Committee (SFEC 2015-078), and an anonymous, self-reported online questionnaire was administered to 72 DHDTS at the University of Portsmouth Dental Academy (UPDA) in the UK, and to 83 DHDTS at La Trobe Rural Health School in Australia. Completion of the survey was taken as consent to participate in the study. The survey was distributed over the four-week examination period, when both the UK and Australian students were 6 months into their academic year. Qualtrics ${ }^{\mathrm{TM}}$ software used for the survey captured the students' year of study and age. Gender was not captured, as this would identify the very small number of male DHDTS. The survey consisted of five well-used measurement 
instruments, which all had excellent reliability and validity, and included the: Dental Environment Stress questionnaire (DES);15 Depression Anxiety Stress Scales (DASS21); ${ }^{19}$ Scales of Psychological Well-Being (SPWB); ${ }^{12}$ Valuing Questionnaire (VQ); ${ }^{13}$ and the Adult Hope Scale (AHS). ${ }^{14}$

The DES (Table 2) was chosen as it is the most widely used measurement in the dental setting, within the existing literature. ${ }^{15} \mathrm{~A}$ modified version was used, ${ }^{20}$ consisting of thirtynine items describing stressors specifically relating to dental undergraduate training. The response to each item was rated on a five-point scale: $0=$ not pertinent, $1=$ not stressful, 2 = slightly stressful, $3=$ moderately stressful and $4=$ very stressful. The mean score was calculated for each item of the DES to evaluate stress levels and a total score was calculated by summing all responses. The items were grouped into five stressor domains: living accommodation, personal factors, educational environment, academic work and clinical factors.

The DASS $-21,{ }^{19}$ a shorter version of the full survey (DASS - 42), was adopted. It consisted of three self-reporting scales constructed to measure the negative emotional states of depression, anxiety and stress. Each of these contained 7 items. Participants responded using a 4-point severity and frequency scale to rate the extent to which they had experienced each over the past week: $0=$ did not apply to me at all, $1=$ applied to me to some degree, or some of the time, 2 = applied to me to a considerable degree, or a good part of the time and $3=$ applied to me very much, or most of the time. Separate scores for depression, anxiety and stress were calculated by summing the scores for each. These were then multiplied by 2 to fit with the DASS - 42 scale. Table 3 shows the DASS authors' recommended cut-off scores for the labels of 'normal', 'moderate' and 'severe', in relation to depression, anxiety and stress, which is based on Lovibond and Lovibond's normative data. ${ }^{19}$

The shorter version of the SPWB, ${ }^{12}$ was used. It comprised of six self-reporting scales consisting of 9 items, which measured the dimensions of autonomy, environmental mastery, personal growth, positive relations with others, purpose in life, and selfacceptance. The response to each item was rated on a six-point scale: $1=$ strongly disagree, 2 = moderately disagree, 3 = slightly disagree, 4 = slightly agree, 5 = moderately agree and $6=$ strongly agree. There is no specific score for defining high or low well-being, therefore thresholds for 'pure' positive and negative scores were set at $>36$ and $<27$ 
respectively for the purpose of the study, to provide an indication of participants trends in the direction of either positive or negative psychological well-being.

The VQ, ${ }^{13}$ a self-reporting 10-item scale, was adopted to measure the extent to which DHDTS lived out their values across their life. The VQ was used to measure how much participants were living according to their personal values, rather than what their values were per se. This instrument was originally designed to track clients' progress towards living according to their values in Acceptance and Commitment Therapy, ${ }^{21}$ but it is not client specific and has been used with the general population. Indeed, a very recent study has also used the VQ as one of the instruments in a survey of Australian undergraduate students. ${ }^{22}$ Participants responded using a six-point format ranging from $0=$ not at all true, through to $6=$ completely true. The 10-item scale has 2 subscales: 5 items which measures progress towards valued living and 5 items which measures obstruction towards valued living. Subscale scores were calculated by summing the scores of the 5 items in each sub-scale to get a score for the progress domain and a score for the obstruction domain.

Finally, the AHS, ${ }^{14}$ a self-reporting 12-item scale was selected. It consists of two subscales that measure 'agency' (goal-directed energy) and 'pathways' (planning to accomplish goals). Of the total 12 items, 4 measure agency and 4 measure pathway. The remaining 4 items are 'fillers'. Participants responded using an eight-point scale: $1=$ definitely false, $2=$ mostly false, $3=$ somewhat false, $4=$ slightly false, $5=$ slightly true, $6=$ somewhat true, $7=$ mostly true, $8=$ definitely true. Individual scores for agency hope and pathway hope were calculated by summing the scores of the 4 items in each. There is no specific score defining high and low hope, however an early study by the author of the AHS, suggested that 'high hope' and 'low hope' equated to a combined agency and pathway score of $>60$ and $<35$ respectively. ${ }^{23}$

Cronbach's alpha ranged from 0.68 to 0.88 for all of the scales (SPWB: 0.88 (Aus), 0.87 (UK); DASS-21: 0.88 (Aus), 0.82 (UK); AHS: 0.88 (Aus), 0.78 (UK); DES: 0.80 (Aus), 0.69 (UK); VQ: 0.68 (Aus), 0.69 (UK)). The reliability of all the scales was within the acceptable limits, albeit the VQ for both study samples, and the DES for the UK sample was at the lower end. The correlations of the scales (Table 4) were what we would have expected. For example, hope agency correlated highly positively with the sub-scales of the SPWB, such as purpose in life and self-acceptance, and negatively correlated with the depression sub-scale of the DASS-21. 
Statistical analysis carried out using SPSS V22 ${ }^{\mathrm{TM}}$ included frequency distributions, reliability analysis, and correlation analysis. The data were checked for normality, kurtosis and skew. Mann-Whitney $\mathrm{U}$ tests with Bonferroni corrections were used. The level for a statistically significant difference was set at $p<0.002$.

\section{RESULTS}

The response rate was $58 \%$ for the UK $(n=42)$, and $55 \%$ for Australia $(n=46)$. The mean age for the UK was 26 (5.1) years, with a range of 19 to 39 years. The mean age for Australia was 23 (6.33) years, with a range of 18 to 49 years.

Table 5 compares the domain-specific sources of stress mean DES scores for the UK and Australia. Scores for living accommodation, personal factors, academic work and clinical factors showed similar trends for both the UK and Australian students, and were similar levels to those reported in a previous study. ${ }^{7}$ However, within the domain of the educational environment, the scores were significantly higher $(p<0.002)$ for the Australian students than the UK students.

Table 6 presents the stressors within the educational environment domain of the DES for each year of study for the UK and Australia. Sources of stress within the educational environment were not reported as particularly high (above 3 ) in any year of study for the UK students. For the Australian students, Year 1 scores were similar to the UK. For both Year 2 and Year 3 DHDTS, criticism about academic or clinical work was reported as a high source of stress, with approachability of staff also a high source of stress to the Year 3 students.

Table 7 shows the dimensions of SPWB mean scores for UK and Australia. Both UK and Australia mean scores were above the threshold for a negative score $(<27)$, with a trend towards the threshold of a positive score $(>36)$, for both groups, in all dimensions. There was no statistical difference between the two groups.

Table 8 shows the mean scores for the DASS-21, AHS and VQ for the UK and Australia. The majority of depression and stress scores for both groups were within the recommended cut-off scores ${ }^{19}$ for the label 'mild' (10-13 for depression, 15-18 for stress). The cut-off scores for anxiety fell within the label 'moderate' (10-14), and were higher than those reported in the previous UK study. ${ }^{7}$ Both UK and Australian students reported fairly high levels of agency hope, pathway hope, and progress towards values; students also 
reported fairly low levels of obstruction towards values. There was no statistical difference between the two groups.

\section{DISCUSSION}

Four out of the five domain-specific sources of stress mean DES scores showed similar trends for both the UK and Australia, and were comparable to reported findings in a previous study of UK DHDTS. ${ }^{7}$ The scores also corresponded with the existing literature of what dental students, in diverse educational settings, had previously reported in studies as being their main sources of stress which could potentially lead to burnout ${ }^{1-6}$

Living accommodation and personal factors were not particularly stressful DES domains for either the UK or Australian DHDTS, and were similar to a previous UK study. ${ }^{7}$ This present study also showed a trend that both UK and Australian DHDTS perceived the domain of academic work, which included items such as fear of failing the course/year, examinations, and fear of being able to catch up if falling behind as more stressful than clinical factors (Table 5), which is in contrast to the recent SA study of perceived stress in DHDTS, ${ }^{9}$ which showed that third year students reported individual clinical factors, and not academic factors, as their top sources of stress. However, we must show caution in direct comparisons with this study, as the SA researchers modified the DES from a 5-point scale which was used in the current study, to a 3-point scale, which has less range. It is not too surprising that the academic domain was perceived as stressful, as western culture puts great emphasis on students getting good grades, ${ }^{21}$ and is evident within the previous literature which has reported 'competition for grades' as one of the high sources of stress in dental undergraduate training. ${ }^{1,2}$

Although the domain of the educational environment, which included items such as criticism about academic or clinical work, approachability of staff, and expectation versus reality of dental school, was not perceived as stressful to the UK DHDTS, it was however, significantly higher $(p<0.002)$ for the Australian DHDTS. In particular, both Years 2 and Years 3 Australian DHDTS reported criticism about academic or clinical work as a high source of stress (which was similar to that reported by DHDTS in the SA study ${ }^{9}$ ), with approachability of staff an additional high source of stress to the Year 3 students (Table 6). These were also the same sources of stress reported by third year dental students in a recent Australian study. ${ }^{24}$ In this study the authors attributed the reported stressors to the 
increased contact time with staff in the clinical setting, and frustration for students to try and adopt differing techniques advised by different clinical staff. The reasons for the differences between DHDTS in our study could be explained by the variation of how the curriculum is delivered in the UK and Australia (Table 1). Firstly, due to the tight scheduling of their programme, the Australian DHDTS had only a very short summer break between completing Year 2 and commencing Year 3 studies. Therefore, feeling fatigued may have negatively influenced the students' perception of the teaching staff feedback. Secondly, the Australian curriculum puts a strong focus on clinical experience in diverse rural settings for students in Year 3, and perhaps the concern of treating patients safely in an unfamiliar environment was an added source of stress. This would be in line with the literature that suggests that the significance (meaningfulness) given to a situation can create a stressful response if something one cares about is at stake. ${ }^{25}$ In contrast, the UK DHDTS in our study had a six-week summer break between all years of study, and had gained most of their clinical experience in the same primary care setting throughout their undergraduate programme. However, it was interesting to note that the Year 1 Australian DHDTS did not report criticism about academic or clinical work as particularly stressful. Indeed, the Australian DHDTS reported it lower than that of the Year 1 UK DHDTS, which may reflect the 'flipped classroom' approach of the Australian delivery of the pre-clinical sessions.

Both the UK and Australian DHDTS reported scores of psychological well-being that were indicative of students who were positively-functioning individuals (Table 7). Measures of continual development and openness to experience (personal growth), goals and intentions (purpose in life), and the ability to respond to other individuals (positive relations with others), were particularly high for both groups, which in addition to being the characteristics of a good clinician, also corresponded with the literature associating wellbeing dimensions with meaning. ${ }^{26-29}$ For example, studies have shown that having a high purpose in life and compassion for oneself and others, can bring meaning to stressful situations by interpreting the stress as a challenge (enhancing), rather than a threat (debilitating) ${ }^{25,29}$ Furthermore, self-acceptance of one's work requires the motivation to endure the stress of receiving (negative) feedback in exchange for the learning opportunity of receiving it. ${ }^{31}$ Indeed, the Australian DHDTS in this study reported criticism about academic or clinical work as highly stressful. However, at the same time the students also reported high scores of personal growth. These findings are comparable with a recent qualitative study in which DHDTS described how they utilised "negative" feedback as an 
opportunity to learn and grow, even in the instances of conflicting opinions from the clinical teaching staff. 8

Neither group reported levels of depression or stress that would be considered outside of the normal range ${ }^{19}$ (Table 8), and were comparable with a previous UK study. ${ }^{7}$ However, the mean score levels of anxiety for both the UK and Australian DHDTS were in the range considered as moderate, ${ }^{19}$ and were higher than those reported in the previous UK study. ${ }^{7}$ The difference in anxiety scores was most likely due to the timing of the distribution of the survey. The previous survey in the UK centre was administered in the month of July, which corresponded to the end of the academic year, and examinations and results were published. The survey for this study was administered in the examination period, when anxiety levels would be expected to be higher.

The reported levels of agency hope and pathway hope were similar for both the UK and Australian students (Table 8). Establishing goals is strongly linked to a sense of purpose which provides direction and a sense of meaning in life. ${ }^{26,27}$ Furthermore, research has shown that 'high hope' students focus on success, not failure, and can sustain their motivation by utilising goal setting as a challenge for high academic achievement, even under circumstances of stress. For example, studies have shown how positive emotions from successful goal attainment encourage individuals to set 'stretch goals' for higher academic achievement, whilst also having the ability to alter their pathway to goal pursuit, or indeed, to 'let go' of problematic goals if need be. ${ }^{23,32,33}$

The scores for progress to values, and obstruction to values (Table 8), showed that both the UK and Australian DHDTS reported to be living according to their values. Valued living is the successful consequence of meaningful goal pursuit that is intrinsically reinforced, and serves an individual's core values. ${ }^{13,21}$ For example, an individual may have a core value of making a difference to society, and therefore choose a career (goal) as a health care professional (e.g. DT/OHT), that serves that value. Moreover, having core values is a quality of professionalism that is of critical importance to future clinicians involved in patient care.

Most research on dental student stress has focused on the negative aspects of stress. ${ }^{1-3}$ This has resulted in some researchers advocating a curriculum change to reduce stress in the dental undergraduate programme. ${ }^{4,20}$ However, stress often results from activities that are meaningful, and reducing stress may result in reducing the meaning of the activity. ${ }^{25-28}$ Minor curriculum changes such as calibration of staff feedback could be explored, however 
the researchers in this study also recommend interventions to raise the awareness of the meaningful relationship of stress as a coping mechanism to build resiliency. ${ }^{31}$ Providers of education would do well to take the holistic view of psychological well-being as not merely the presence or absence of stress, but rather the degree to which individuals are fully functioning to realise their true potential (Waterman, 1993). ${ }^{34}$

\section{CONCLUSION}

This study was an investigation into perceived sources of stress and well-being in DHDTS in a school in the UK and a school in Australia. Within the limits of this study, reported sources of stress and well-being for these two cohorts of DHDTS showed similar trends to the previous initial studies of UK and SA DHDTS undergraduate education.

This study showed that DHDTS in the UK and Australia reported numerous and intensive stressors, specifically in the academic and educational domains of the DES. However, at the same time, the majority in both groups reported high levels of positive psychological well-being and normal ranges of stress and depression, and a moderate range of anxiety. This study further demonstrated that DHDTS undergraduate training in both the UK and Australia was indeed perceived as academically and educationally stressful, however, in line with previous studies, the students reported scores as positively-functioning individuals. 


\section{REFERENCES}

1. Alzahem AM, Alaujan AH, Van der Molen HT, Schmidt HG, Zamakhshary MH. Stress amongst dental students: a systematic review. Eur J Dent Educ 2011: 15: 8-18.

2. Elani HW, Allison P J, Kumar RA, et al. A systematic review of stress in dental students. J Dent Educ 2014: 78: 226-242.

3. Al-Samadani $\mathrm{KH}, \mathrm{Al}-\mathrm{Dharrab} \mathrm{A}$. The perception of stress among clinical dental students. World J Dent 2013: 4: 24-28.

4. Divaris K, Barlow PJ, Chendea SA, Cheong WS, Dounis A, Dragan IF, Vrazic D. The academic environment; the students' perspective. Eur J Dent Educ 2008: 12: 120-130.

5. Atalayin C, Balkis M, Teze H, Onal B, Kayrak G. The prevalence and consequences of burnout on a group of preclinical dental students. Eur J Dent Educ 2015: 9: 356-363.

6. Campos JA, Jordani PC, Zucoloto ML, Bonafé FS, Maroco J. Burnout syndrome among dental students. Rev Bras Epidemiol 2012: 15: 155-165.

7. Harris M, Wilson JC, Holmes S, Radford DR. Perceived stress and well-being amongst dental hygiene and dental therapy students. Br Dent J 2017: 222: 101-106.

8. Harris M, Wilson JC, Hughes S, Radford DR. Does stress in a dental hygiene and dental therapy undergraduate programme contribute to a sense of well-being in the students? Br Dent J 2017: 223: 22-26.

9. Gordon, NA, Rayner, CA, Wilson, VJ, Crombie, K, Shaikh, AB, Yasin-Harnekar, S. Perceived stressors of oral hygiene students in the dental environment. Afr J Hlth Prof Educ 2016: 8: 20-24.

10. Dahan $\mathrm{H}$, Bedos $\mathrm{C}$. A typology of dental students according to their experience of stress: a qualitative study. J Dent Educ 2010: 74: 95-103.

11. Laurence B, Williams C, Eiland D. Depressive symptoms, stress, and social support among dental students at a historically black college and university. J American College HIth 2009: 58: 65-63.

12. Ryff CD. Happiness is everything, or is it? Explorations on the meaning of psychological well-being. J Pers Soc Psychol 1989: 57: 1069-1081.

13. Smout M, Davies M, Burns N, Christie A. Development of the valuing questionnaire (VQ). J Context Behav Sci 2014: 3: 164-172.

14. Snyder CR, Harris C, Anderson J R, et al. The will and the ways: development and validation of an individual-differences measure of hope. J Pers Soc Psychol 1991: 60: 570585 .

15. Garbee WH, Zucker SB, Selby GR. Perceived sources of stress among dental students. J Am Dent Assoc 1980: 100: 853-857. 
16. Humphris G, Blinkhorn A, Freeman R, et al. Psychological stress in undergraduate dental students: baseline results from seven European dental schools. Eur J Dent Educ 2002: 6: 22-29.

17. Gorter, RC. Work stress and burnout among dental hygienists. Int J Dent Hyg 2005: 3: 88-92.

18. Lopresti, S. Stress and the dental hygiene profession: Risk factors, symptoms, and coping strategies. Can J Dent Hyg 2014: 48: 63-69.

19. Lovibond SH and Lovibond PF. Manual for the Depression Anxiety Stress Scales. $2^{\text {nd }}$ ed. Sydney: Psychology Foundation, 1995.

20. Naidu RS, Adams JS, Simeon D, Persad S. Sources of stress and psychological disturbance among dental students in the West Indies. J Dent Educ 2002: 66: 021-1030.

21. Dahl JC, Plumb J C, Stewart I, Lungdren T. The art and science of valuing in psychotherapy: Helping clients discover, explore, and commit to valued action using acceptance and commitment therapy. Oakland, CA: New Harbinger, 2009: 1-12.

22. Fischer TD, Smout MF, Delfabbro PH. The relationship between psychological flexibility, early maladaptive schemas, perceived parenting and psychopathology. J Contex Behav Sci 2016: 5: 169-177.

23. Snyder CR, LaPointe AB, Crowson JJ, Early SE. Preferences of high and low hope people for self-referential input. Cognition and Emotion 1998: 12: 807-823.

24. Astill S, Ricketts N, Singh LA, Kurtz D, Gim YH, Huang B. Environmental and perceived stress in Australian dental undergraduates: Preliminary outcomes. J Dent Res Dent Clin Dent Prospect 2016: 10: 270-279.

25. McGonigal K. The upside of stress. London: Vermilion, 2015: 63-122.

26. Baumeister F, Vohs D. The pursuit of meaningfulness in life. In CR Snyder and SJ Lopez (eds) Handbook of positive psychology. New York: Oxford University Press, 2005: 608-618.

27. Feldman DB, Snyder C R. Hope and the meaningful life: Theoretical and empirical associations between goal-directed thinking and life meaning. J Soc Clin Psychol 2005: 24: 401-421.

28. Baumeister RF, Vohs KD, Aaker JL, Gabinskey EN. Some key differences between a happy life and a meaningful life. J Pos Psychol 2013: 8: 505-516.

29. Stillman TF, Baumeister RF. Uncertainty, belongingness, and four needs for meaning. Psychol Inq 2009: 20: 249-251.

30. Neff K. Self-compassion: Stop beating yourself up and leave security behind. New York: HarperCollins, 2011: 107-187. 
31. Crum AJ, Salovey $P$, Achor S. Rethinking stress: The role of mindsets in determining the stress response. J Pers Soc Psychol 2013: 104: 716-733.

32. Snyder CR, Shorey HS, Cheavens J, Mann Pulvers K, Adams VH, Wiklund C. Hope and academic success in college. J Educ Psychol 2002: 4: 820-826.

33. Snyder CR, Cheavens J, Sympson SC. Hope: an individual motive for social commerce. Group Dymanics: Theory, Research, and Practice 1997: 1: 107-118.

34. Waterman, AS. Two conceptions of happiness: Contrasts of personal expressiveness (eudaimonia) and hedonic enjoyment. J Pers Soc Psychol 1993: 64: 678-691. 
Table 1. DHDTS curriculum for centres in UK and Australia showing module titles and credits assigned to each module

\begin{tabular}{|c|c|c|}
\hline \multirow{2}{*}{$\begin{array}{l}\text { DHDTS } \\
\text { year of } \\
\text { study }\end{array}$} & $\begin{array}{l}\text { University of Portsmouth Dental } \\
\text { Academy, UK }\end{array}$ & La Trobe Rural Health School, Australia \\
\hline & $\begin{array}{l}\text { Teaching and learning modules } \\
\text { (number of credits) }\end{array}$ & $\begin{array}{l}\text { Teaching and learning modules (number } \\
\text { of credits) }\end{array}$ \\
\hline \multirow[t]{6}{*}{ Year 1} & $\begin{array}{l}\text { 1.Foundations of Clinical Practice } \\
\text { (20) }\end{array}$ & $\begin{array}{l}\text { 1. Introduction to Oral Health Sciences } \\
\text { (30) }\end{array}$ \\
\hline & 2.Introduction to Behavioural Science & 2. Individual Determinants of Health (15) \\
\hline & $\begin{array}{l}\text { (20) } \\
\text { (20) }\end{array}$ & 3. Human Biosciences A (15) \\
\hline & (20) & 4. Social Determinants of Health (15) \\
\hline & $\begin{array}{l}\text { 4.Personal and Professional } \\
\text { Development (20) }\end{array}$ & 5. Human Biosciences B (15) \\
\hline & 5.Pre-Clinical Practice (40) & $\begin{array}{l}\text { 6. Pre-Clinical Oral Health Practice } \\
\text { (30)ף }\end{array}$ \\
\hline
\end{tabular}

Year 2 1.Advanced Behavioural Science (20) 1. Principles of Public Health Practice

2.Advanced Human Science (20) (15) †

3.Dental Radiology and Dental 2. Medicine for Dentistry A (15)

Imaging (20)介

4.Professional Development and

Team Work (20)

5.Clinical Practice (40)
3. Oral Medicine, Special Needs

Dentistry and Pharmacology (15)‡

4. Research in Dentistry (15)§

5. Clinical Oral Health Practice (60)ף
Year $3 \quad$ 1.Clinical Practice in the Wider

Community (20)†

2.Management and Leadership for

DCP practice (20)

3.Oral Surgery and Oral Medicine (20)‡

4. Research in DCP practice (20)§

5.Comprehensive Clinical Practice (40)
1. Evidence Based Oral Health Practice (30)

2. Adult Dental Therapy (15)

3. Integrated Oral Health (75)

\footnotetext{
$\uparrow, \ddagger, \S$ : similar modules delivered at different times within the UK and Australian curriculum

T: Dental Radiology and Dental Imaging is a standalone module in Year 2 in UK; and integrated into Oral Health Practice modules in Years 1, 2, and 3 in Australia
} 
Table 2. Dental Environment Stress questionnaire items and domains.

DES Individual item stressor Domain

Moving away from home

Living accommodation

Environment in which to study

Lack of home atmosphere

Other problems with accommodation

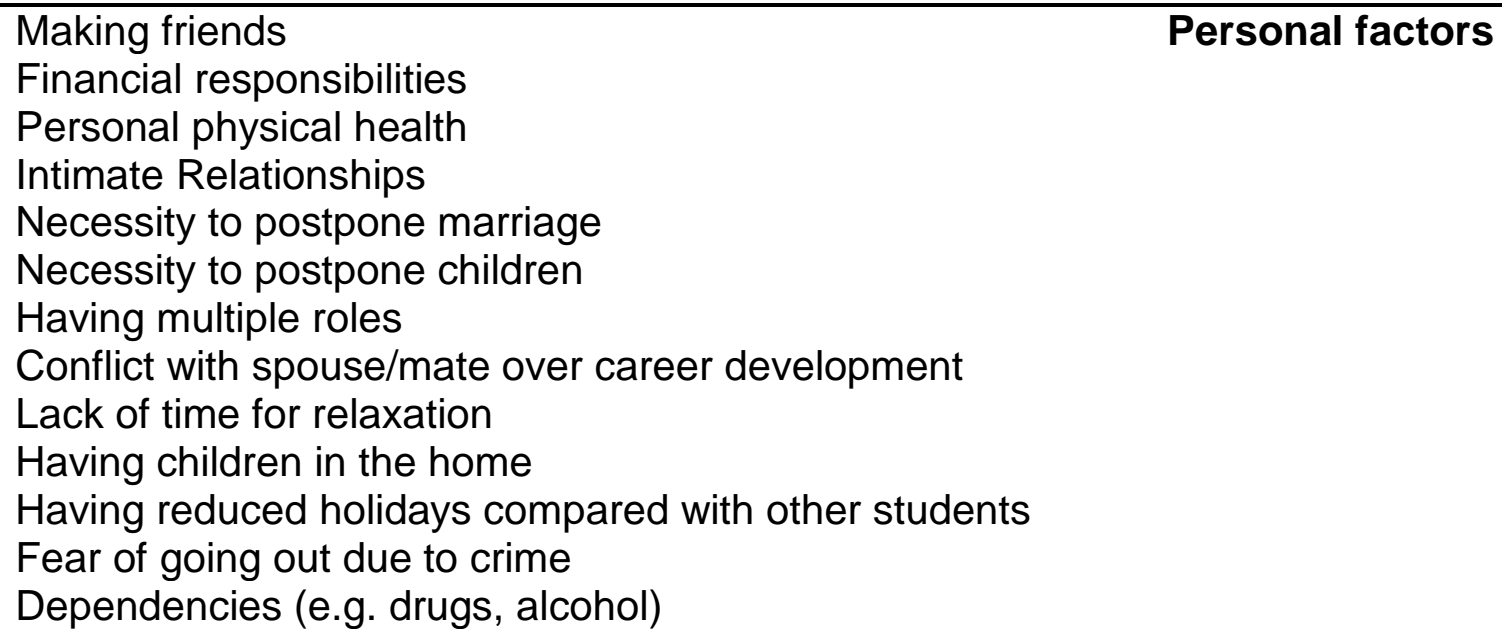

Concerns about manual dexterity

Clinical factors

Transition from preclinical to clinical

Learning precision manual skills

Completing clinical requirements

Concern about treatment grades awarded

Difference in opinion between clinical staff concerning

treatment

Shortage of allocated clinical time

Patient management

Confidence in own clinical decision making 
Table 3. Cut-off scores for DASS - 21 severity labels (normal, moderate, severe)

\begin{tabular}{llll}
\hline \multirow{2}{*}{ Normal } & Depression & Anxiety & Stress \\
\cline { 2 - 4 } Mild & $0-9$ & $0-7$ & $0-14$ \\
Moderate & $10-13$ & $8-9$ & $15-18$ \\
Severe & $14-20$ & $10-14$ & $19-25$ \\
Extremely severe & $21-27$ & $15-19$ & $26-33$ \\
\hline
\end{tabular}


Table 4. Correlations of scales for UK and Australia

\begin{tabular}{|c|c|c|c|c|c|c|c|c|c|c|c|c|c|c|c|c|c|c|}
\hline UPDA & $\begin{array}{l}\text { DASS-21 } \\
\text { STRESS }\end{array}$ & \begin{tabular}{|l|} 
DASS-21 \\
ANXIETY
\end{tabular} & $\mid \begin{array}{c}\text { DASS-21 } \\
\text { DEPRESS }\end{array}$ & $\begin{array}{c}\text { AHS } \\
\text { AGENCY }\end{array}$ & \begin{tabular}{|c|} 
AHS \\
PATHWAY
\end{tabular} & $\begin{array}{c}\text { DES } \\
\text { LIVING } \\
\text { ACC }\end{array}$ & $\begin{array}{c}\text { DES } \\
\text { PERSONAL }\end{array}$ & $\begin{array}{l}\text { DES } \\
\text { EDUC }\end{array}$ & $\begin{array}{c}\text { DES } \\
\text { ACADEMIC }\end{array}$ & $\begin{array}{c}\text { DES } \\
\text { CLINICAL }\end{array}$ & VQ PROG & $\begin{array}{c}\text { VQ } \\
\text { OBSTRUCT }\end{array}$ & $\begin{array}{l}\text { SPWB } \\
\text { PRWO }\end{array}$ & $\begin{array}{c}\text { SPWB } \\
\text { AUTON }\end{array}$ & SPWB EM & SPWB PG & SPWB PIL & SPWB SA \\
\hline DASS-21 STRESS & 1 & $.687^{7 /}$ & $.634^{n t}$ & -.203 & -.160 & .184 & .166 & .303 & $.549^{\circ "}$ & .076 & -.096 & $.393^{*}$ & -.203 & -.235 & -.342 & -.272 & -.148 & -.260 \\
\hline DASS-21 ANXIETY & $.687^{\prime \prime}$ & 1 & $.528^{* *}$ & -.321 & -.204 & .143 & -.030 & 208 & $.431^{* \prime}$ & -.125 & -.032 & .196 & -.168 & -.203 & -.114 & -.169 & -.121 & -.228 \\
\hline DASS-21 DEPRESS & $.634^{\prime \prime}$ & $.528^{* 1}$ & 1 & $-.472^{* *}$ & $-.355^{*}$ & 207 & $.327^{*}$ & $.438^{* \prime}$ & $.427^{* 1}$ & 181 & $-.487^{* \prime}$ & $.432^{* *}$ & $-.479^{\prime \prime}$ & $-.474^{\prime \prime}$ & $-.668^{* *}$ & $-.504^{4}$ & $-.581^{* *}$ & $-.705^{*}$ \\
\hline AHS AGENCY & -.203 & -.321 & $-.472^{* *}$ & 1 & $.642^{* \prime}$ & .073 & -.226 & $-.440^{* \prime \prime}$ & $-.423^{\prime \prime}$ & -.148 & $.553^{* *}$ & -244 & 246 & $654^{* *}$ & $.502^{\mathrm{m}}$ & $.435^{*}$ & $.590^{* *}$ & .644" \\
\hline AHS PATHWAY & -.160 & -204 & $-.355^{*}$ & $.642^{\prime \prime}$ & 1 & -.064 & -.115 & -.157 & -.073 & -.196 & $.447^{\prime \prime}$ & -.050 & 318 & $.649^{\prime \prime}$ & $.485^{\circ \prime}$ & $.531^{\prime \prime}$ & $.520 *$ & $.432^{\circ}$ \\
\hline DES LIVING ACC & .184 & .143 & 207 & .073 & -.064 & 1 & .003 & .034 & .211 & -.005 & -.164 & .128 & -.272 & .016 & -.064 & -.018 & -.065 & -208 \\
\hline DES PERSONAL & .166 & -.030 & $.327^{*}$ & -.226 & -.115 & .003 & 1 & $.472^{\prime \prime}$ & 294 & $.435^{* \prime}$ & $-357^{*}$ & $.417^{*}$ & -302 & $-.400^{*}$ & $-.723^{* \prime}$ & -.156 & -.277 & $-440^{\circ}$ \\
\hline DES EDUC & .303 & 208 & $.438^{* \prime}$ & $-.440^{\prime \prime}$ & -.157 & .034 & $.472^{\prime \prime}$ & 1 & $.583^{* \prime}$ & $.414^{*}$ & $-.362^{*}$ & $.337^{*}$ & -234 & $-.398^{*}$ & $-.454^{* \prime}$ & -.024 & -.238 & $-.498^{*}$ \\
\hline DES ACADEMIC & $.549^{\prime \prime}$ & $.431^{\prime \prime}$ & $.427^{\prime \prime}$ & $-.423^{\prime \prime}$ & -.073 & .211 & .294 & $.583^{\prime \prime}$ & 1 & $.355^{\circ}$ & -.164 & $341^{*}$ & .000 & -.135 & -265 & -.074 & .008 & -.306 \\
\hline DES CLINICAL & .076 & -.125 & .181 & -.148 & -.196 & -.005 & $.435^{* \prime}$ & $.414^{*}$ & $.355^{*}$ & 1 & -.147 & .242 & .002 & -.020 & $-.396^{*}$ & .136 & .065 & $-365^{*}$ \\
\hline VQ PROG & -.096 & -.032 & $-.487^{* \prime}$ & $.553^{* \prime}$ & $.447^{* *}$ & -.164 & $-357^{*}$ & $-.362^{*}$ & -.164 & -.147 & 1 & -251 & $.675^{* \prime}$ & $.501^{\prime \prime}$ & $.607^{\prime \prime \prime}$ & $.455^{\circ \prime}$ & $.652^{* *}$ & $.668^{* *}$ \\
\hline VQ OBSTRUCT & $.393^{*}$ & .196 & $.432^{* \prime \prime}$ & -.244 & -.050 & .128 & $.417^{*}$ & $.337^{*}$ & $.341^{*}$ & .242 & -251 & 1 & -265 & -326 & $-.544^{* \prime}$ & $-.429^{\circ}$ & -315 & -331 \\
\hline SPWB PRWO & -.203 & -.168 & $-.479^{* *}$ & .246 & .318 & -.272 & -302 & -234 & .000 & .002 & $.675^{*}$ & -265 & 1 & $.439^{*}$ & $.596^{* \prime}$ & $.349^{*}$ & $497^{* *}$ & $.5300^{\circ+}$ \\
\hline SPWB AUTON & -.235 & -.203 & $-.474^{* *}$ & $.654^{*}$ & $649^{* \prime}$ & .016 & $-.400^{*}$ & $-.398^{*}$ & -.135 & -.020 & $.501^{*}$ & -.326 & $.439^{*}$ & 1 & $.686^{* *}$ & $.615^{* \prime}$ & $.711^{* *}$ & $.545^{* \prime}$ \\
\hline SPWB EM & -.342 & -.114 & $-668^{* *}$ & $.502^{*}$ & $.485^{* *}$ & -.064 & $-.723^{*}$ & $-.454^{* *}$ & -265 & $-.396^{*}$ & $.607^{* *}$ & $-.544^{*}$ & $.596^{* 4}$ & $686^{* \prime}$ & 1 & $.462^{* *}$ & $.721^{* *}$ & $641^{*}$ \\
\hline SPWB PG & -.272 & -169 & $-.504^{* *}$ & $.435^{*}$ & $.531^{\prime \prime \prime}$ & -.018 & -.156 & -.024 & -.074 & .136 & $.455^{* \prime}$ & $-.429^{*}$ & $.349^{*}$ & $.615^{* *}$ & $.462^{\prime \prime}$ & 1 & $.630^{* *}$ & $400^{\circ}$ \\
\hline SPWB PIL & -.148| & -.121 & $-.581^{* *}$ & $.590^{\prime \prime}$ & $.520 *$ & -.065 & - .277 & -.238 & . 008 & .065 & .652" & -315 & $.497^{* \prime}$ & $.711^{* \prime}$ & $.721^{* 1}$ & $.630^{\circ *}$ & 1 & $.673^{*}$ \\
\hline SPWB SA & -.260 & .228 & $-.705^{* *}$ & $644^{*+1}$ & $.432^{*}$ & -.208 & $-.440^{*}$ & $-.498^{*+}$ & -.306 & $-365^{*}$ & $.668^{*+}$ & -.331 & $.530^{* *}$ & $.545^{* *}$ & $641^{* *}$ & $.400^{*}$ & $.673^{*+}$ & \\
\hline AUS & $\begin{array}{l}\text { DASS-21 } \\
\text { STRESS }\end{array}$ & \begin{tabular}{|l|} 
DASS-21 \\
ANXIETY
\end{tabular} & $\mid \begin{array}{c}\text { DAS-21 } \\
\text { DEPRESS }\end{array}$ & $\begin{array}{c}\text { AHS } \\
\text { AGENCY }\end{array}$ & \begin{tabular}{|c|} 
AHS \\
PATHWAY
\end{tabular} & $\begin{array}{c}\text { AHS } \\
\text { LIVING } \\
\text { ACC }\end{array}$ & $\begin{array}{c}\text { DES } \\
\text { PERSONAL }\end{array}$ & $\begin{array}{l}\text { DES } \\
\text { EDUC }\end{array}$ & $\begin{array}{c}\text { DES } \\
\text { ACADEMIC }\end{array}$ & $\begin{array}{c}\text { DES } \\
\text { CLINICAL }\end{array}$ & VQ PROG & \begin{tabular}{c|}
$\mathrm{VQ}$ \\
OBSTRUCT
\end{tabular} & $\begin{array}{l}\text { SPWB } \\
\text { PRWO }\end{array}$ & $\begin{array}{c}\text { SPWB } \\
\text { AUTON }\end{array}$ & SPWB EM & SPWB PG & SPWB PIL & SPWB SA \\
\hline DASS-21 STRESS & 1 & $.760^{\circ}$ & $.765^{*}$ & -.297 & $-.329^{*}$ & .210 & .109 & $.437^{* \prime}$ & $.508^{8 *}$ & $.403^{*}$ & -.264 & $.486^{* 1}$ & $-.651^{* *}$ & $-.381^{*}$ & $-.700^{*}$ & $-.373^{*}$ & $-.633^{* *}$ & $-.528^{*}$ \\
\hline DASS-21 ANXIETY & $.760^{*}$ & 1 & $.712^{* *}$ & -255 & $-.330^{*}$ & 292 & .182 & $.350^{*}$ & $.410^{\circ *}$ & .197 & $-.407^{*}$ & 193 & $-.436^{* *}$ & $-.363^{*}$ & $-.573^{* *}$ & -.169 & $-.430^{* *}$ & $-.555^{*}$ \\
\hline DASS-21 DEPRESS & $.765^{*}$ & $.712^{* *}$ & 1 & $-.375^{*}$ & $-387^{*}$ & .141 & .098 & $.351^{*}$ & $.436^{* \prime}$ & $.381^{*}$ & -207 & $.345^{*}$ & $-.466 *$ & -330 & $-.684^{* *}$ & $-406^{\circ}$ & $-.644^{\prime \prime}$ & $-.544^{*}$ \\
\hline AHS AGENCY & -.297 & -.255 & $-.375^{*}$ & 1 & $.795^{* *}$ & .212 & .192 & .012 & -.171 & -.196 & $.667^{* *}$ & -.118 & $.398^{*}$ & $.443^{* *}$ & $.572^{* *}$ & $.444^{* *}$ & $.576^{*}$ & $.768^{* 1}$ \\
\hline AHS PATHWAY & $-329^{*}$ & $-.330^{*}$ & $-.387^{*}$ & $.795^{*}$ & 1 & .111 & .201 & -.061 & -.183 & -.118 & $.591^{*}$ & -.140 & $.361^{*}$ & $.392^{*}$ & $.537^{* *}$ & $.469^{* *}$ & $.487^{*}$ & .671" \\
\hline DES LIVING ACC & .210 & 292 & .141 & .212 & .111 & 1 & $.557^{* 1}$ & $.637^{*+}$ & $.438^{* 1 *}$ & .228 & .128 & $.327^{*}$ & .173 & 144 & -204 & 275 & -.022 & 037 \\
\hline DES PERSONAL & .109 & 182 & .098 & .192 & .201 & $.557^{* *}$ & 1 & $.608^{* *}$ & $.351^{*}$ & .294 & .064 & 121 & .014 & 131 & -.094 & 162 & .014 & .051 \\
\hline DES EDUC & $.437^{*}$ & $.350^{*}$ & $.351^{*}$ & .012 & -.061 & $637^{* \prime}$ & $.608^{*}$ & 1 & $.764^{* \prime}$ & $.573^{*}$ & .024 & $.566^{* \prime}$ & -.318 & -097 & $-.426^{* \prime}$ & -.031 & -295 & -.128 \\
\hline DES ACADEMIC & $.508^{* \prime}$ & $.410^{*}$ & $.436^{* *}$ & -.171 & -.183 & $.438^{* \prime}$ & $.351^{*}$ & $.764^{* *}$ & 1 & $.736^{* *}$ & -.071 & $.711^{* *}$ & -.285 & $-.376^{*}$ & $-397^{*}$ & -.127| & $-.407^{*}$ & -.283 \\
\hline DES CLINICAL & $.403^{*}$ & .197 & $.381^{*}$ & -.196 & -.118 & .228 & .294 & $.573^{*+}$ & $.736^{* \prime}$ & 1 & .020 & $.656^{* \prime}$ & -.251 & -276 & $-.393^{*}$ & -.226 & $-.482^{*}$ & -180 \\
\hline VQ PROG & -.264 & $-.407^{*}$ & -207 & $.667^{*}$ & $.591^{* \prime \prime}$ & .128 & .064 & .024 & -.071 & .020 & 1 & .066 & .268 & 335 & $.486^{\circ \prime}$ & .334 & $.374^{*}$ & $.669^{*}$ \\
\hline VQ OBSTRUCT & $.486^{\prime \prime}$ & .193 & $.345^{*}$ & -.118 & -.140 & $.327^{*}$ & 121 & $.566^{* *}$ & $.711^{* \prime}$ & $.656^{*}$ & .066 & 1 & -.314 & -.313 & $-.427^{*}$ & -.197| & $-.438^{* *}$ & -.251 \\
\hline SPWB PRWO & $-.651^{\prime \prime}$ & $-.436^{* *}$ & $-.466^{* *}$ & $.398^{*}$ & $.361^{*}$ & .173 & 014 & -.318 & -285 & -251 & .268 & -314 & 1 & $.394^{*}$ & $.604^{* *}$ & $.580^{*}$ & $647^{*}$ & $.480^{\circ}$ \\
\hline SPWB AUTON & $-381^{*}$ & $-.363^{*}$ & -.330 & $.443^{* \prime}$ & $.392^{*}$ & .144 & .131 & -.097 & $-.376^{*}$ & -.276 & .335 & -.313 & $.394^{*}$ & 1 & $.447^{* *}$ & $.370^{*}$ & $.493^{*}$ & .607" \\
\hline SPWB EM & $-.700^{* *}$ & $-.573^{* *}$ & $-.684^{* *}$ & $.572^{* \prime}$ & $.537^{* *}$ & - 204 & -.094 & $-.426^{* \prime}$ & $-397^{*}$ & $-.393^{*}$ & $.486^{*}$ & $-.427^{*}$ & $.604^{* 4}$ & $.447^{* *}$ & 1 & $.511^{* *}$ & $.771^{*}$ & $.817^{* *}$ \\
\hline SPWB PG & $-.373^{*}$ & -169 & $-.406^{*}$ & $.444^{\prime \prime}$ & $.469^{*+4}$ & .275 & .162 & -.031 & -.127 & -.226 & .334 & -197 & $.580^{\circ+1}$ & $.370^{*}$ & $.511^{* 1}$ & 1 & $.749^{* *}$ & $.525^{*}$ \\
\hline SPWB PIL & $-.633^{\prime \prime}$ & $-.430^{* *}$ & $-.644^{* *}$ & $.576^{\prime \prime}$ & $.487^{* 1}$ & -.022 & .014 & -.295 & $-.407^{*}$ & $-.482^{*+4}$ & $.374^{*}$ & $-.438^{\prime \prime}$ & $.647^{* *}$ & $.493^{* \prime}$ & $.771^{\prime \prime}$ & $.749^{\circ 1}$ & 1 & $.713^{*+}$ \\
\hline SPWB SA & $-.528^{\prime \prime}$ & $-.555^{* *}$ & $-.544^{* *}$ & $.768^{\prime \prime}$ & $671^{*+}$ & .037 & .051 & -.128 & -283 & -.180 & $.669^{*+}$ & -251 & $.480^{\circ+4}$ & $.607^{* *}$ & $.817^{* \prime}$ & $.525^{\circ \prime}$ & $.713^{\prime \prime}$ & \\
\hline
\end{tabular}

**. Correlation is significant at the 0.01 level 
Table 5. Domain-specific sources of stress mean DES scores for UK and Australia

\begin{tabular}{llll}
\hline $\begin{array}{l}\text { DES Domain (max score } \\
\text { within each domain) }\end{array}$ & $\begin{array}{l}\text { Mean (SD) } \\
\text { UK (n=39) }\end{array}$ & $\begin{array}{l}\text { Mean (SD) } \\
\text { Aus (n=41) }\end{array}$ & $p$ value \\
\cline { 2 - 4 } Living accommodation (16) & $6.51(3.60)$ & $8.26(3.77)$ & 0.019 \\
Personal factors (52) & $16.87(6.55)$ & $17.84(7.99)$ & 0.270 \\
Education environment (20) & $7.41(2.77)$ & $11.15(4.14)$ & $0.000^{*}$ \\
Academic work (32) & $20.41(5.34)$ & $21.95(7.13)$ & 0.107 \\
Clinical factors (36) & $19.70(5.86)$ & $19.20(7.83)$ & 0.823
\end{tabular}

${ }^{\star}$ Bonferroni correction $p<0.002$ 
Table 6. The stressors within the educational environment domain of the DES for each year of study for UK and Australia (high stress score $=3$ or above)

\begin{tabular}{llll}
\hline Year & Sources of stress within the educational environment domain & $\begin{array}{l}\text { Mean (SD) } \\
\text { UK }\end{array}$ & $\begin{array}{l}\text { Mean (SD) } \\
\text { Aus }\end{array}$ \\
\cline { 2 - 3 } 1 & Expectation versus reality of dental school & $2.00(1.09)$ & $2.47(1.18)$ \\
Approachability of staff & $1.64(1.03)$ & $2.00(1.12)$ \\
Criticism about academic or clinical work & $2.36(1.03)$ & $2.06(1.03)$ \\
Rules and regulations of the dental school & $1.18(0.60)$ & $1.71(0.92)$ \\
& Discrimination due to race, nationality, gender or social class & $0.73(0.65)$ & $1.00(1.00)$ \\
& & \\
& & $1.77(1.01)$ & $2.71(1.39)$ \\
& Expectation versus reality of dental school & $1.77(0.73)$ & $2.57(0.79)$ \\
Approachability of staff & $2.46(0.78)$ & $3.14(0.69)$ \\
Criticism about academic or clinical work & $1.54(0.78)$ & $2.29(1.13)$ \\
Rules and regulations of the dental school & $0.54(0.51)$ & 0.43() $.53)$ \\
Discrimination due to race, nationality, gender or social class & & \\
& $1.60(0.99)$ & $2.71(1.31)$ \\
& Expectation versus reality of dental school & $1.13(0.35)$ & $3.06(1.08)$ \\
Approachability of staff & $1.80(0.86)$ & $3.18(0.80)$ \\
Criticism about academic or clinical work & $1.20(0.68)$ & $2.65(1.32)$ \\
Rules and regulations of the dental school & $0.73(0.70)$ & $1.47(1.46)$
\end{tabular}


Table 7. Dimensions of SPWB mean scores for UK and Australia

\begin{tabular}{llll}
$\begin{array}{l}\text { SPWB dimension } \\
\text { (MAX SCORE }= \\
54)\end{array}$ & $\begin{array}{l}\text { Mean (SD) } \\
\text { UK }(n=34)\end{array}$ & $\begin{array}{l}\text { Mean (SD) } \\
\text { Aus }(n=36)\end{array}$ & $p$ value \\
\cline { 2 - 4 } $\begin{array}{l}\text { Positive relations } \\
\text { with others }\end{array}$ & $40.73(8.45)$ & $39.29(7.30)$ & 0.317 \\
$\begin{array}{l}\text { Autonomy } \\
\text { Environmental }\end{array}$ & $36.97(7.26)$ & $33.54(6.29)$ & 0.064 \\
mastery & $37.78(6.25)$ & $34.30(7.58)$ & 0.086 \\
Personal growth & $44.36(5.07)$ & $42.39(5.95)$ & 0.213 \\
Purpose in life & $43.41(6.59)$ & $39.25(5.89)$ & 0.006 \\
Self-acceptance & $39.68(7.72)$ & $35.50(9.13)$ & 0.057 \\
\hline
\end{tabular}


Table 8. Mean scores of DASS-21, AHS and VQ for UK and Australia

\begin{tabular}{|c|c|c|c|}
\hline $\begin{array}{l}\text { DASS-21, AHS and } \\
\text { VQ subscales (max } \\
\text { score within each } \\
\text { subscale) }\end{array}$ & $\begin{array}{l}\text { Mean (SD) } \\
\text { UK } \\
(n=42)\end{array}$ & $\begin{array}{l}\text { Mean (SD) } \\
\text { Aus } \\
(n=46)\end{array}$ & $p$ value \\
\hline \multicolumn{4}{|l|}{ DASS-21 } \\
\hline Depression (42) & $11.57(9.18)$ & $13.06(10.18)$ & 0.440 \\
\hline Anxiety (42) & $10.78(8.85)$ & $13.08(9.58)$ & 0.216 \\
\hline Stress (42) & 17.43 (8.07) & $17.20(9.96)$ & 0.850 \\
\hline \multicolumn{4}{|l|}{ AHS } \\
\hline Agency (32) & $25.67(3.67)$ & $22.45(5.93)$ & 0.010 \\
\hline Pathway (32) & 25.30 (3.55) & $21.9095 .97)$ & 0.004 \\
\hline \multicolumn{4}{|l|}{ VQ } \\
\hline Progress (30) & $19.84(5.74)$ & $17.74(6.94)$ & 0.237 \\
\hline Obstruction (30) & $10.32(5.48)$ & $13.25(6.88)$ & 0.048 \\
\hline
\end{tabular}

